\title{
A Comparative Analysis of Tumors and Plasma Circulating Tumor DNA in 145 Advanced Cancer Patients Annotated by 3 Core Cellular Processes
}

\author{
Kristian Larson ${ }^{1} \oplus$, Radhamani Kannaiyan ${ }^{2}$, Ritu Pandey ${ }^{3}$, Yuliang Chen ${ }^{4}$, Hani M. Babiker ${ }^{5}$ \\ and Daruka Mahadevan ${ }^{5, *}$ \\ 1 University of Arizona College of Medicine, 1501 N Campbell Ave, Tucson, AZ 85724, USA; \\ kris7c@email.arizona.edu \\ 2 Vidant Medical Center, 2100 Stantonsburg Rd, Greenville, NC 27834, USA; radha.maran@gmail.com \\ 3 Department of Cellular and Molecular Medicine, University of Arizona Cancer Center, \\ 1515 N Campbell Ave, Tucson, AZ 85724, USA; ritu@email.arizona.edu \\ 4 University of Arizona Cancer Center, 1515 N Campbell Ave, Tucson, AZ 85724, USA; \\ yuliangchen@email.arizona.edu \\ 5 Early Phase Clinical Trials Program, University of Arizona Cancer Center, 1515 N Campbell Ave, Tucson, \\ AZ 85724, USA; hanibabiker@arizona.edu \\ * Correspondence: mahadevand@uthscsa.edu; Tel.: +1-520-260-4843
}

Received: 20 January 2020; Accepted: 14 March 2020; Published: 16 March 2020

\begin{abstract}
Matched-targeted and immune checkpoint therapies have improved survival in cancer patients, but tumor heterogeneity contributes to drug resistance. Our study categorized gene mutations from next generation sequencing (NGS) into three core processes. This annotation helps decipher complex biologic interactions to guide therapy. We collected NGS data on 145 patients who have failed standard therapy (2016 to 2018). One hundred and forty two patients had data for tissue (Caris MI/X) and plasma cell-free circulating tumor DNA (Guardant360) platforms. The mutated genes were categorized into cell fate (CF), cell survival (CS), and genome maintenance (GM). Comparative analysis was performed for concordance and discordance, unclassified mutations, trends in TP53 alterations, and PD-L1 expression. Two gene mutation maps were generated to compare each NGS platform. Mutated genes predominantly matched to CS with concordance between Guardant 360 $(64.4 \%)$ and Caris $(51.5 \%)$. TP53 alterations comprised a significant proportion of the mutation pool in Caris and Guardant $360,14.7 \%$ and $13.1 \%$, respectively. Twenty-six potentially actionable gene alterations were detected from matching ctDNA to Caris unclassified alterations. The CS core cellular process was the most prevalent in our study population. Clinical trials are warranted to investigate biomarkers for the three core cellular processes in advanced cancer patients to define the next best therapies.
\end{abstract}

Keywords: molecular targeted therapy; drug resistance; neoplasm; high-throughput nucleotide sequencing; DNA mutational analysis; liquid biopsy

\section{Introduction}

Precision oncology strives to develop new targeted and immune therapies to improve overall survival (OS) [1]. Molecular profile-based clinical trials, including IMPACT [2] and WINTHER [3], have demonstrated a clear positive impact of matched-targeted therapies (MTT) against patient-specific gene alterations over chemotherapy. Small molecule inhibitors in various stages of development are designed to block key oncogenic signaling pathways. For example, BRAF and ALK inhibitors are 
examples that have demonstrated increased OS in melanoma and non-small cell lung cancer (NSCLC), respectively $[4,5]$.

Studies have shown that tumor molecular profiles are multilayered and interactive. TP53 mutations remain a clinical challenge and are associated with poor outcomes across many cancer subtypes [6-8]. PD-L1 status correlates to poor prognoses and predictive of responding to anti-PD-1 agents $[9,10]$. Breast adenocarcinoma (BAC) treated with PARP inhibitors up-regulating PD-L1 expression highlights the benefits of anti-PD-L1 therapy for this resistant state [11].

The development of MTTs that encompass complete molecular profiles is quintessential to personalized cancer treatments [2,12]. A review grouped a dozen regulatory signaling pathways into categories that reflect three fundamental cellular processes: cell fate (CF), cell survival (CS), and genome maintenance (GM) [13]. By categorizing the molecular profile into CF, CS, and GM, we aimed to integrate a comprehensive summary of driver and passenger mutations and display the corresponding tumor heterogeneity. We hypothesize that categorizing the mutational profile of each individual tumor to $\mathrm{CF}, \mathrm{CS}$, and GM will elucidate cellular processes (patterns) that provide a better understanding of tumor evolution and the development of drug resistance. In addition, since TP53 is the most common mutated gene in a myriad of cancer subtypes, TP53 is given special attention. Considering immune suppression is a key factor in modulating the tumor microenvironment, PD-L1 expression is also included in our analysis. By comparing next generation sequencing (NGS) platforms that assay tumor tissue and plasma circulating tumor DNA (ctDNA), we explored concordance versus discordance to discover tumor heterogeneity.

Patients' genetic alterations are increasingly being revealed through a variety of NGS platforms. Interpretation and clinical decision-making of the results can be challenging. To address these issues, we present an integrated study of 145 patients enrolled in phase 1 clinical trials and are the first to compare 25 different cancer subtypes with data from two NGS platforms and gene category annotation.

\section{Results}

\subsection{Cell Survival (CS) Mutations Dominate Cell Fate (CF) and Genome Maintenance (GM) Mutations}

NGS platforms detected a total of 173 mutated genes from 142 patients. These 173 mutated genes categorized to $53.2 \%(n=92) \mathrm{CS}, 37.6 \%(n=65) \mathrm{CF}$, and $9.2 \%(n=16) \mathrm{GM}$ (Figure 1$)$. The same trend CS $>$ CF > GM followed at the platform level with CS $64.4 \%$ in Guardant 360 and $51.5 \%$ in Caris (Table 1).

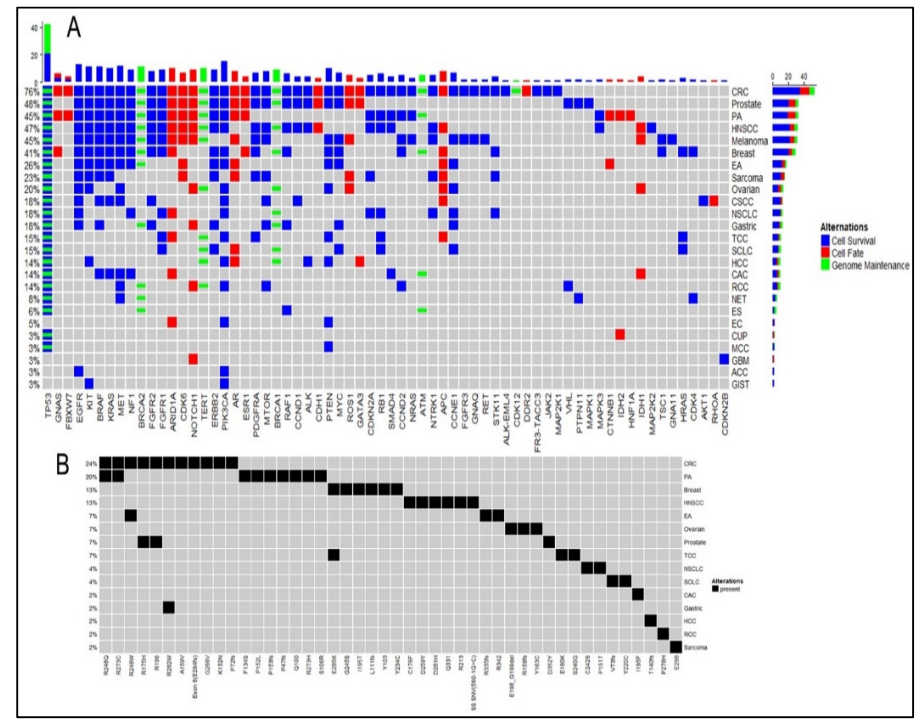

Figure 1. Mutation map (A) showing frequency of gene mutations detected by Guardant360 across all and individual cancer subtypes and their associated categories of cell survival, cell fate, and genome maintenance. (B) Matched TP53 alterations detected by both Guardant360 and Caris in cancer subtypes. 
Table 1. Cancer subtypes and sample size that are stratified in cell fate (CF), cell survival (CS), and genome maintenance (GM) by both next generation sequencing platforms, Caris and Guardant360. Raw values represent quantities of gene mutations per category. Values in parentheses represent gene percentages within the sample group. This table shows major trends that drive tumorigenesis with overall trends at the bottom as the total. Gene designations of CF, CS, and GM also displayed for reference. See appendix for abbreviations.

\begin{tabular}{|c|c|c|c|c|c|c|c|}
\hline Cancer Subtype & $\mathbf{Q}$ & G-CF (\%) & G-CS (\%) & G-GM (\%) & C-CF (\%) & C-CS (\%) & C-GM (\%) \\
\hline Adenoid cystic carcinoma & 1 & $0(0)$ & $2(100)$ & $0(0)$ & $0(0)$ & $0(0)$ & $0(0)$ \\
\hline Breast adenocarcinoma & 10 & $10(15.4)$ & $41(63.1)$ & $14(21.5)$ & $6(12.8)$ & $25(53.2)$ & $16(34.0)$ \\
\hline $\begin{array}{l}\text { Carcinoma of unknown } \\
\text { primary }\end{array}$ & 2 & $1(33.3)$ & $1(33.3)$ & $1(33.3)$ & $1(100)$ & $0(0)$ & $0(0)$ \\
\hline Cholangiocarcinoma & 3 & $3(18.8)$ & $9(56.3)$ & $4(25.0)$ & $2(28.6)$ & $4(57.1)$ & $1(14.3)$ \\
\hline Colorectal carcinoma & 29 & $74(25.1)$ & $178(60.3)$ & $43(14.6)$ & $48(33.3)$ & 60 (41.7) & $36(25.0)$ \\
\hline $\begin{array}{c}\text { Cutaneous squamous cell } \\
\text { carcinoma }\end{array}$ & 2 & $3(18.8)$ & $11(68.8)$ & $2(12.5)$ & $4(36.4)$ & $6(54.5)$ & $1(9.1)$ \\
\hline Endometrial carcinoma & 2 & $2(33.3)$ & $4(66.7)$ & $0(0)$ & $0(0)$ & $0(0)$ & $0(0)$ \\
\hline Esophageal adenocarcinoma & 5 & $5(14.3)$ & $23(65.7)$ & $7(20.0)$ & $2(12.5)$ & $10(62.5)$ & $4(25.0)$ \\
\hline $\begin{array}{l}\text { Esophageal squamous cell } \\
\text { carcinoma }\end{array}$ & 1 & $0(0)$ & $2(33.3)$ & $4(66.7)$ & $0(0)$ & $0(0)$ & $0(0)$ \\
\hline Gastric adenocarcinoma & 3 & $1(5.9)$ & $13(76.5)$ & $3(17.6)$ & $0(0)$ & $6(54.5)$ & $5(45.5)$ \\
\hline $\begin{array}{l}\text { Gastrointestinal stromal } \\
\text { tumor }\end{array}$ & 2 & $0(0)$ & $6(100)$ & $0(0)$ & $1(25.0)$ & $3(75.0)$ & $0(0)$ \\
\hline Glioblastoma multiforme & 1 & $1(50)$ & $1(50)$ & $0(0)$ & $0(0)$ & $1(100)$ & $0(0)$ \\
\hline $\begin{array}{l}\text { Head and neck squamous } \\
\text { cell carcinoma }\end{array}$ & 9 & $15(20.3)$ & $48(64.9)$ & $11(14.9)$ & $11(25.6)$ & $22(51.2)$ & $10(23.3)$ \\
\hline Hepatocellular carcinoma & 1 & $2(18.2)$ & $5(45.5)$ & $4(36.4)$ & $1(14.3)$ & $4(57.1)$ & $2(28.6)$ \\
\hline Melanoma & 9 & $10(16.9)$ & $43(72.9)$ & $6(10.2)$ & $6(25.0)$ & $13(54.2)$ & $5(20.8)$ \\
\hline Merkel cell carcinoma & 1 & $0(0)$ & $3(60.0)$ & $2(40.0)$ & $0(0)$ & $0(0)$ & $0(0)$ \\
\hline Neuroendocrine tumor & 2 & $0(0)$ & $14(53.8)$ & $12(46.2)$ & $1(50.0)$ & $0(0)$ & $1(50.0)$ \\
\hline Non-small cell lung cancer & 3 & $2(9.1)$ & $16(72.7)$ & $4(18.2)$ & $0(0)$ & $20(83.3)$ & $4(16.7)$ \\
\hline Ovarian carcinoma & 6 & $4(12.5)$ & $17(53.1)$ & $11(34.4)$ & $2(13.3)$ & $9(60.0)$ & $4(26.7)$ \\
\hline Pancreatic adenocarcinoma & 26 & $16(15.0)$ & $70(65.4)$ & $21(19.6)$ & $23(21.5)$ & $58(54.2)$ & $26(24.3)$ \\
\hline Prostate adenocarcinoma & 11 & $30(25.6)$ & $68(58.1)$ & $19(16.2)$ & $7(30.4)$ & $8(34.8)$ & $8(34.8)$ \\
\hline Renal cell carcinoma & 3 & $1(7.7)$ & $9(69.2)$ & $3(23.1)$ & $0(0)$ & $5(50.0)$ & $5(50.0)$ \\
\hline Sarcoma & 7 & $4(12.9)$ & $21(67.7)$ & $6(19.4)$ & $0(0)$ & $3(60.0)$ & $2(40.0)$ \\
\hline Small cell lung carcinoma & 2 & $1(6.3)$ & $9(56.3)$ & $6(37.5)$ & $0(0)$ & $4(57.1)$ & $3(42.9)$ \\
\hline Transitional cell carcinoma & 4 & $2(8.7)$ & $13(56.5)$ & $8(34.8)$ & $2(13.3)$ & $9(60.0)$ & $4(26.7)$ \\
\hline TOTAL & 145 & $187(18.6)$ & $627(62.4)$ & $191(19.0)$ & $117(22.3)$ & $270(51.5)$ & $137(26.1)$ \\
\hline
\end{tabular}

GENE DESIGNATIONS Cell fate: APC, AR, ARID1A, ARID2, ASXL1, ATRX, AXIN1, BCOR, CDH1, CDK6, CDK8, CREBBP, CTNNB1, DAXX, DDR2, DNMT1, DNMT3A, EP300, ESR1, EZH2, FAM123B (AMER1), FBXW7, FOXL2, GATA1, GATA2, GATA3, GNAS, H3F3A, HH, HIST1H3B, HNF1A, IDH1, IDH2, KDM5C, KDM6A, KLF4, KMT2A, KMT2C, KMT2D, MEN1, MITF, MLL3, NF2, NOTCH1, NOTCH2, PAX5, PBRM1, PHF6, PRDM1, PTCH1, RHOA, RNF43, ROS1, RUNX1, SETBP1, SETD2, SF3B1, SMARCA4, SMARCB1, SMO, SPOP, SRSF2, TET2, U2AF1, WT1. Cell survival: ABL1, AKT1, AKT2, ALK, ALK-EML4, BCL2, BMPR1A, BRAF, CARD11, CASP8, CBL, CCND1, CCND2, CCND3, CCNE1, CDC73, CDK4, CDKN1B, CDKN2A, CDKN2B, CEBPA, CHEK2, CIC, CRKL, CRLF2, CSF1R, CYLD, DICER1, EGFR, EP300, ERBB2, ERBB3, FGF10, FGF3, FGF4, FGFR1, FGFR2, FGFR3, FGFR3-TACC3, FLT3, FUBP1, GNA11, GNAQ, GNAS, HRAS, JAK1, JAK2, JAK3, KIT, KRAS, MAP2K1, MAP2K2, MAP3K1, MAPK1, MAPK3, MCL1, MDM2, MED12, MEK1, MET, MPL, MTOR, MYC, MYD88, NF1, NFE2L2, NPM1, NRAS, NTRK1, NTRK3, PDGFRA, PIK3CA, PIK3R1, PPP2R1A, PTEN, PTPN11, RAF1, RB1, RET, RICTOR, SDHD, SMAD2, SMAD4, SOCS1, STK11, TGFbR2, TNFAIP3, TP53, TRAF7, TSC1, TSHR, VHL. Genome maintenance: ATM, BAP1, BLM, BRCA1, BRCA2, BRIP1, CDK12, CHEK2, MLH1, MSH2, MSH6, PALB2, STAG2, TERT, TP53, WRN. 
When analyzed at the cancer subtype level, 15 of 25 cancer subtypes exhibited a trend of CS > GM > CF. Despite having fewer genes, GM contributed to more alterations than CF. Seven cancer subtypes also followed a trend of CS dominance, but CF and GM swapped positions. Only esophageal squamous cell carcinoma (ESCC) $(n=1)$ demonstrated a trend of GM dominance followed by CS and CF. Aberrations from these trends are observed in carcinoma of unknown primary (CUP) and neuroendocrine tumors (NET), which both represent limited patient sampling. Paired analysis using Fisher's exact tests for these three cellular processes from results combined from both platforms showed no significant $p$-value indicating there is no association between these processes (Table S1A), and they occur independent of each other. Testing individual platform results show association between the occurrence of CS and CF ( $p=0.008)$ on Caris platform and between CS and GM on both Caris $\left(p=6.9 \times 10^{-19}\right)$ and Guardant360 $(p=0.01)$. There was no significant association found between CF and GM on any platform. Patients were divided by their age $(<60-y r$ vs. $>60-y r)$ into two groups and these three processes were tested for prevalence in either of the age group (Table S1B). No association was found with age and occurrence of any of these three processes and no association was found with TP53 mutations. We tested this on both individual platforms and combined platform results.

The trends demonstrated in the cancer subtypes generally agree between both platforms. In the cases of cholangiocarcinoma and prostate adenocarcinoma, there is platform discrepancy between the contributions of GM and CF. As described previously in the limited patient samples, platform trend disagreement was observed most significantly in ESCC, CUPS, and NETs but a larger dataset is needed for statistical confirmation.

\subsection{TP53 is the Most Frequent Mutation}

Guardant 360 and Caris detected a total of 1005 and 524 specific alterations of all mutated genes, respectively. Of these, TP53 comprised a significant proportion at $13.1 \%(n=132)$ and $14.7 \%(n=77)$, respectively. Fifty-eight of these TP53 mutations matched at specific alteration level across the platform. Matched TP53 alterations in colorectal cancer (CRC) dominated $29.3 \%(n=17)$, followed by pancreatic adenocarcinoma $17.2 \%(n=10)$, and BAC $12.1 \%(n=7)$. Platform-matched TP53 alterations appeared substantially in CRC; there were four of R175H and R273C, three of R248Q and R282W, and two of R196, R248W, and R273H alterations. The BAC also contained platform-matched TP53 alterations, including two of E285K and G245S. TP53 has the highest frequency of the mutations. We tested for two-way associations with the three cellular processes across both platforms for all patients (Table S1C). Our results showed that the GM process has a significant association with TP53 mutational status in patients $\left(p=2.2 \times 10^{-16}\right)$, however the CS and CF processes have no significant association with TP53 mutation status in patients. Patients divided into two groups by age ( $>60-\mathrm{yr}$ and $<60-\mathrm{yr})$ were tested for association with TP53 mutation status (Table S1B) with no association found.

\subsection{Trend in PD-L1 Status}

Twenty patients tested positive for PD-L1 by Caris immunohistochemical (IHC) staining (Figure 2). Although head and neck squamous cell carcinoma (HNSCC) and pancreatic adenocarcinoma contain the largest number of positive IHC stains ( 5 and 4 , respectively), HNSCC (55.5\%), TCC (50\%), GIST $(50 \%)$, and NET $(50 \%)$ represent the greatest proportion of positive PD-L1 stains per cancer subtype. Pancreatic adenocarcinoma (15.4\%) and CRC (3.4\%) entailed the least positive PD-L1 stains per cancer subtypes.

\subsection{Marked Discordance Across the Platforms}

Overall, the data show significant discordance in gene mutations across the platforms (Figure 3). At the individual patient level, the mean discordance per patient was 5.3 (range: 0-39). No discordance was detected in six patients. The mean concordance was 1.54 per patient (range: 0-9). 


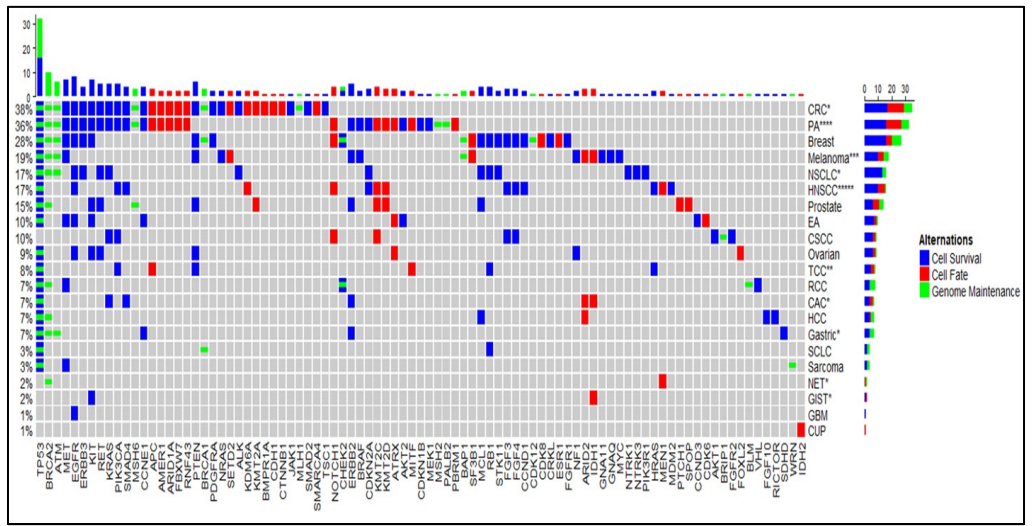

Figure 2. Mutation map showing frequency of gene mutations detected by Caris linked to cancer subtypes and the categories of cell survival, cell fate, and genome maintenance. PD-L1 positive tissue-based IHC found in cancer subtype groups are marked $\left(^{*}\right)$ and the number is equivalent to patients.
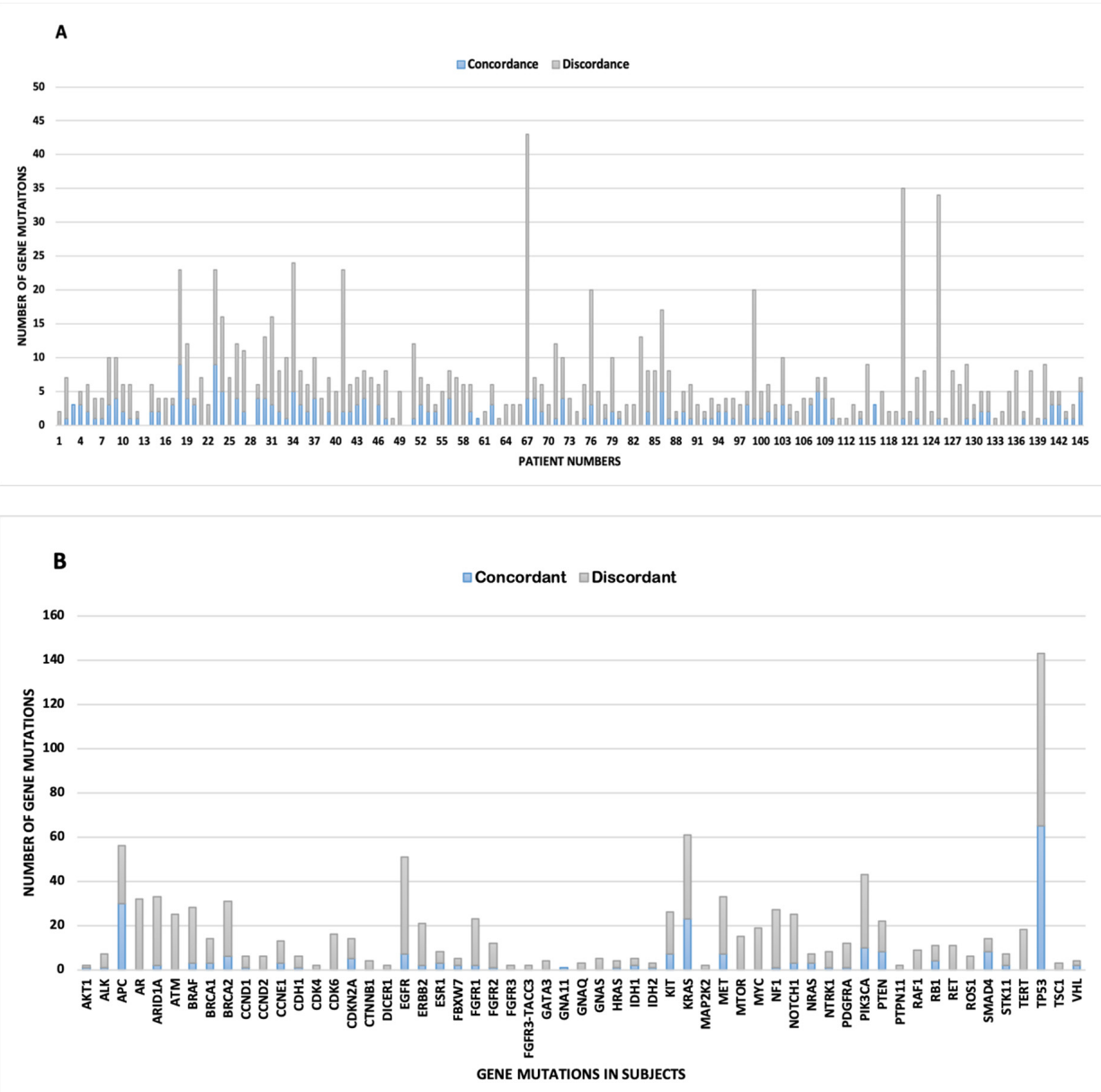

Figure 3. Concordance (blue) and discordance (gray) between gene mutations detected by tissue-based DNA (Caris) and plasma cell-free DNA (Guardant360) next generation sequencing. (A) Quantity of gene mutations stack-plotted per de-identified patient number. Discordance shows intra-patient genetic heterogeneity. (B) Quantity of gene alterations stack-plotted per mutated genes demonstrates driver and passenger gene mutations that contribute to intra-tumor heterogeneity. Gene mutations that displayed zero concordance and one discordant gene mutation were removed for clarity, and include ARID2, ATRX, DDR2, ERBB3, HNF1A, JAK2, MAP2K1, MLH1, and NTRK3. 
At the pooled genes level, 223 genes were concordant and 760 genes were discordant. TP53 represented the highest frequency of concordant gene 29.1\% $(n=65)$ followed by APC $13.5 \%(n=30)$, KRAS 10.3\% $(n=23)$, and PIK3CA 4.5\% $(n=10)$. Interestingly, discordance followed a similar trend with TP53 10.3\% $(n=78)$, EGFR 5.8\% $(n=44)$, KRAS 5.0\% $(n=38)$, and PIK3CA 4.3\% $(n=33)$.

Discordant genes were stratified into the three core cellular processes resulting in CS (61\%), CF $(20 \%)$, and GM $(19 \%)$. This trend was roughly comparable to the stratified mutations of the overall cancer subtypes.

\subsection{Identification of Potentially Actionable Mutations}

The Caris-MI/X NGS platform analyzes tumor-only exon mutations in oncogenes and tumor suppressors. In contrast, the Gaurdant360 NGS platform analyzes cfDNA in tumors versus normal donor volunteer whole exome sequencing (WES) (ages: 20-40-yr), i.e., reference normal DNA. Plasma cfDNA from patients with mutations can detect up to $0.1 \%$ mutant allele frequencies (MAFs) from a background of cfDNA extracted from healthy donors and reported as acquired somatic mutations by digital sequencing algorithms [14]. An actionable mutation is defined as a genetic aberration in the DNA (e.g., activating mutation) when detected in a patient's tumor, and would be expected or predicted to affect a response to a targeted treatment available in basket or umbrella clinical trials, FDA-approved treatments, or be available for off-label treatment [15]. Guardant360 detected genes were found in 19 of 142 patients that matched an exact alteration in the Caris unclassified mutation section (GaDCUS) (Table 2). We found one matching alteration in 16 patients and several in the remaining three patients. GaDCUS appeared frequently in the CRC $(21.1 \%)$. Also, four mutated genes appeared across multiple patients. ARID1A appeared in the BAC, CRC, and NSCLC. CDKN2A appeared in sarcoma and pancreatic adenocarcinoma groups. ALK appeared in CRC and HNSCC. NF1 appeared in CRC and pancreatic adenocarcinoma. For example, the ALK (F1408L, G1473E) are novel mutations and whether they are sensitive to ALK tyrosine kinase inhibitors is not known but needs further evaluation. Similarly, the AR (P135L, A810T) are also mutants needing further investigation (Table 2).

Table 2. Nineteen patients with Guardant 360 alterations detected in Caris unclassified section (GaDCUS) and 26 discovered somatic alterations that are potentially treatable. Identified gene mutations show the amino acid alteration in parentheses. Alterations are stratified into the three core cellular process categories to seek trends. Parentheses within the stratified columns represent percentages. See appendix for abbreviations.

\begin{tabular}{|c|c|c|c|c|c|}
\hline PT & Diagnosis & GaDCUS & CF (\%) & CS $(\%)$ & GM (\%) \\
\hline 5 & $\begin{array}{c}\text { Breast } \\
\text { adenocarcinoma }\end{array}$ & HRAS (R41W) & $0(0)$ & $1(100)$ & $0(0)$ \\
\hline 9 & $\begin{array}{c}\text { Breast } \\
\text { adenocarcinoma }\end{array}$ & $\begin{array}{l}\text { ARID1A } \\
\text { (L1841L) }\end{array}$ & $1(100)$ & $0(0)$ & $0(0)$ \\
\hline 23 & $\begin{array}{l}\text { Colorectal } \\
\text { carcinoma }\end{array}$ & $\begin{array}{c}\text { ALK (F1480L), } \\
\text { FGFR3 (A734T), } \\
\text { RAF1 (V21M), } \\
\text { TERT (A670V) }\end{array}$ & $0(0)$ & $3(75)$ & $1(25)$ \\
\hline 26 & $\begin{array}{l}\text { Colorectal } \\
\text { carcinoma }\end{array}$ & $\begin{array}{l}\text { ARID1A } \\
(\mathrm{K} 1830 \mathrm{~T})\end{array}$ & $1(100)$ & $0(0)$ & $0(0)$ \\
\hline 33 & $\begin{array}{l}\text { Colorectal } \\
\text { carcinoma }\end{array}$ & NF1 (R2119T) & $0(0)$ & $1(100)$ & $0(0)$ \\
\hline 44 & $\begin{array}{l}\text { Colorectal } \\
\text { carcinoma }\end{array}$ & GATA3 (V338I) & $1(100)$ & $0(0)$ & $0(0)$ \\
\hline 51 & $\begin{array}{c}\text { Esophageal } \\
\text { adenocarcinoma }\end{array}$ & AR (P135L) & $1(100)$ & $0(0)$ & $0(0)$ \\
\hline
\end{tabular}


Table 2. Cont.

\begin{tabular}{|c|c|c|c|c|c|}
\hline PT & Diagnosis & GaDCUS & CF (\%) & CS (\%) & GM (\%) \\
\hline 56 & $\begin{array}{c}\text { Gastric } \\
\text { adenocarcinoma }\end{array}$ & RAF1 (R59H) & $0(0)$ & $1(100)$ & $0(0)$ \\
\hline 68 & $\begin{array}{l}\text { Head and neck } \\
\text { squamous cell } \\
\text { carcinoma }\end{array}$ & ALK (G1473E) & $0(0)$ & $1(100)$ & $0(0)$ \\
\hline 71 & $\begin{array}{l}\text { Hepatocellular } \\
\text { carcinoma }\end{array}$ & $\begin{array}{l}\text { GATA3 } \\
\text { (A319E) }\end{array}$ & $1(100)$ & $0(0)$ & $0(0)$ \\
\hline 75 & Melanoma & AR (A810T) & $1(100)$ & $0(0)$ & $0(0)$ \\
\hline 79 & Melanoma & $\begin{array}{c}\text { NTRK1 } \\
\text { (G595E), } \\
\text { NTRK1 (Q487), } \\
\text { ROS1 (G2031R) }\end{array}$ & $1(50)$ & $1(50)$ & $0(0)$ \\
\hline 84 & $\begin{array}{l}\text { Non-small cell } \\
\text { lung carcinoma }\end{array}$ & RB1 (N690S) & $0(0)$ & $1(100)$ & $0(0)$ \\
\hline 86 & $\begin{array}{l}\text { Non-small cell } \\
\text { lung carcinoma }\end{array}$ & $\begin{array}{c}\text { ARID1A } \\
\text { (L2239P), } \\
\text { ARID1A } \\
\text { (R2057W), } \\
\text { CCNE1 (A53P) }\end{array}$ & $2(66.7)$ & $1(33.3)$ & $0(0)$ \\
\hline 87 & $\begin{array}{l}\text { Ovarian } \\
\text { carcinoma }\end{array}$ & ROS1 (P1941L) & $1(100)$ & $0(0)$ & $0(0)$ \\
\hline 100 & $\begin{array}{c}\text { Pancreatic } \\
\text { ductal } \\
\text { adenocarcinoma }\end{array}$ & NF1 (R1396H) & $0(0)$ & $1(100)$ & $0(0)$ \\
\hline 102 & $\begin{array}{c}\text { Pancreatic } \\
\text { ductal } \\
\text { adenocarcinoma }\end{array}$ & $\begin{array}{l}\text { CDKN2A } \\
(\mathrm{L} 64 \mathrm{P})\end{array}$ & $0(0)$ & $1(100)$ & $0(0)$ \\
\hline 127 & $\begin{array}{c}\text { Prostate } \\
\text { adenocarcinoma }\end{array}$ & MYC (F22L) & $0(0)$ & $1(100)$ & $0(0)$ \\
\hline 136 & Sarcoma & $\begin{array}{l}\text { CDKN2A } \\
\text { (A100P) }\end{array}$ & $0(0)$ & $1(100)$ & $0(0)$ \\
\hline
\end{tabular}

\section{Discussion}

Our study characterized passenger and driver mutations from NGS in tissue-based and plasma ctDNA samples into the three core cellular processes of tumorigenesis [13]. A review of the literature comparing advanced cancer patients' molecular profiles concurrently for tissue based (Caris MI/X) and plasma (Guardant360) by NGS with annotation to the three core cellular processes has not been described before. We identified that CS genes dominated compared to GM and CF genes in our study population. GM and CF genes were prevalent equally. Similar trends were maintained at each platform level as well. Paired analysis using Fisher's exact tests for the three cellular processes combined from both platforms showed no significant P-value, indicating no association and that the processes were independent of each other. Testing individual platforms showed association between CS and CF $(p=0.008)$ on Caris and between CS and GM on both Caris $\left(p=6.9 \times 10^{-19}\right)$ and Guardant360 $(p=0.01)$. Patients divided by age ( $<60-y r$ vs. $>60$-yr) showed no association with TP53 mutations or any of the three cellular processes.

It can be surmised that tumor types with unfavorable growth conditions, such as hypoxia and hypoglycemia, result in selective mutations of genes such as KRAS, BRAF, PIK3CA, and TP53 [15]. These altered pathways lend cancer cells survival advantages by employing strategies such as angiogenesis and GLUT1 upregulation [15,16]. Further studies utilizing this conceptual framework 
through large-scale prospective studies in targeted and immune checkpoint therapy trials are required to validate our analysis.

Patients with ESCC, NET, and CUP revealed mixed results that did not follow the predominant trend. However, these groups had the least number of patients and yielded low statistical power. A study that elucidated the genomic landscape of ESCC in 133 patients found the most frequent somatic mutations included TP53 (93\%), CCND1 (33\%), CDKN2A (20\%), NFE2L2 (10\%), and RB1 (9\%) [17]. These driver mutations of ESCC predominantly belong to the CS and less to the GM and CF processes, which positively compares to our analysis. Innovative clinical trial designs that integrate molecular profiles to the three core pathways to select appropriate MTTs [18] may help prevent or overcome drug resistance. In addition, clinical decision-making about treatment selection would shift from single gene mutations to more comprehensive molecular profile-based approaches. Assessing the three core cellular processes may potentially renovate precision oncology and improve patient survival.

High frequencies of TP53 mutations play a transformative role in tumorigenesis across multiple cancer subtypes [19-21]. Most patients had TP53 mutations with predominance within the CRC group $(29.3 \%)$. TP53 mutations consequently resulted in the highest rates of concordance and discordance between the NGS platforms. Tumor responses to antiangiogenic drugs, such as bevacizumab, have indicated a link to TP53 mutations as a biomarker [22]. Integrating data on specific TP53 alterations with transcriptomics may help guide therapy in addition to a more comprehensive molecular profile.

PD-L1 expression adds another layer of complexity to NGS molecular profiling. Studies have demonstrated aggressive cancer growth with defective anti-tumor immune responses and resistance by immunoediting of PD-L1 [23,24]. Understanding a patient's molecular profile, including copy number amplifications (CNAs), may help predict drug resistance and consequently help tailor a regimen(s) more efficacious and less toxic to normal tissue.

Comparison of alterations detected by tissue based (Caris) versus plasma ctDNA (Guardant360) platforms exhibited marked discordance. Our study included mutations detected at low, intermediate, and high frequencies. These results support other studies that show marked discordance between platform comparisons and the inclusion of low alteration frequencies $[25,26]$. We included all frequency ranges to form a complete genetic profile to demonstrate the degree of intra- and inter-patient tumor heterogeneity. Since plasma ctDNA provides a snapshot or summary of all metastatic sites of cancer within a patient, comparing the detected mutations of a focused tissue biopsy can miss other relevant mutations. A study that conducted a saturation analysis of 21 tumor types concluded that genes with low frequencies should be included in analyses to better comprehend the full implications of defective signaling pathways [27]. Plasma ctDNA analyses have shown therapeutic benefits and can help understand tumor evolution, including mechanisms of resistance such as acquired ESR1 mutations that induce aromatase inhibitor resistance [28] in BAC and EGFR resistance to 1st and 2nd generation EGFR tyrosine kinase inhibitors in NSCLC. This reinforces the practice of following multiple plasma ctDNA samples throughout patient management, especially before progression [29] prior to imaging.

Although we chose the most recent tissue and plasma samples, following patient ctDNA samples at multiple intervals may offer some advantages. For example, a retrospective study of nine metastatic BAC patients demonstrated that more optimal therapies could have been chosen by following changes in ctDNA [29]. A recent joint review by the American Society of Clinical Oncology (ASCO) and College of American Pathologists (CAP) provided contrary evidence in the clinical utility of plasma ctDNA in the early detection of cancer, monitoring treatment or post-treatment residual disease [30]. Several factors influence ctDNA, which include low tumor burden, number of metastatic sites and timing of sample collection during active treatment and/or surgical resection [31]. As supported by a study that evaluated cancer driver genes, our study does not account for all tumor heterogeneity [32]. Guidelines on specimen collection, especially with plasma ctDNA, must be developed to yield consistent results among NGS platforms and to accurately characterize the genetic heterogeneity of cancer. Tissue-based biopsies have shaped approaches to MTT with improved patient outcomes; including ctDNA will likely confer the similar benefits in early phase clinical trials as demonstrated by the TARGET study $[33,34]$. 
Our study revealed potentially actionable alterations. Cross-comparison of NGS in tissue and ctDNA yielded 26 somatic mutations that previously were categorized as variants of unknown significance (VUS). Caris compares a patient's sample to a database of known driver mutations to confirm pathogenic alterations [15]. Guardant360 captures the full spectrum of plasma cell-free DNA (cfDNA) and genetically distinguishes tumor vs. normal DNA to infer clinically relevant alterations [14]. Additionally, Caris assigns alterations that have an unknown growth advantage to the "unclassified" section. Hence, alterations detected by Guardant360 in the Caris unclassified section (GaDCUS) strongly suggest mutations that are somatic and potentially targetable. A study [35] that identified putative germline mutations in ctDNA reported detection of $A P C, A T M, B R C A 1 / 2, C D K N 2 A$, MLH1, NF1, RB1, RET, SMAD4, and TP53. We found these mutations in both our NGS platform analyses except MLH1 in Guardant360. Our GaDCUS mutations matched CDKN2A, NF1, and RB1 as well, which help discern germline and somatic mutations. Our patients' GaDCUS mutations fell into the CS and CF categories approximately equally. We detected one GaDCUS mutation, TERT $(A 670 V)$ in a CRC patient (\#23), that resides in the GM category. Since TERT plays a major role in tumor cell immortality through telomere lengthening, this GaDCUS mutation may have revealed a potential driver that contributed to the pathogenesis of this CRC case [36]. A study of various tumor types identified over 50 gene candidates that mapped to interactive pathways of known major cancer driver genes [37]. By performing NGS on platforms that differ in methodology, we can identify clinically relevant alterations. Studies have utilized software tools such as CHASM and ANNOVAR to statistically determine the significance of driver and passenger gene mutations [38]. When mutations are discovered, these databases can compute more comprehensive analyses of cancer genomes and heterogeneity [39]. Additionally, more complex stratifications can be applied to determine the primary drivers of a patient's tumor growth and guide selection of targeted and immune checkpoint therapies.

\section{Limitations}

Comparing NGS data of tumor biopsy (Caris) to plasma ctDNA (Guardant360) render both a comparative limitation and an illustration of the heterogeneity that exists in advanced cancer patients. This heterogeneity contributes to the significant discordance observed in our analysis. However, it demonstrates the variability of actionable mutations at tumor sites and unpredictable responses to MTT. Our study analyzed a snapshot of time as opposed to following the mutational evolution with time. Following plasma ctDNA samples in real time will help anticipate tumor evolution and provide an opportunity to switch therapy prior to imaging. Tissue-based samples entail greater costs and toxicity of procedure for the patient. Cancer subtype-specific characteristics, such as treatment history, were not accounted for in our diverse study population. Further delineation of the annotated trends should include these measures especially for the potential design of clinical trials.

\section{Materials and Methods}

\subsection{Patient Selection, NGS Platforms, and Sample Acquisition}

Patients with advanced solid tumors who failed standard therapy seen in the Early Phase Therapeutics Program clinic were evaluated for tumor tissue and plasma ctDNA by NGS between March 2016 and November 2018. All patients analyzed were Institutional Review Board (IRB) exempt with protocol title "Analysis of Molecular Profiles of Patients with Advanced Cancer" (IRB number: 1804508570), allowing data collection from Caris life sciences and Guardant Health NGS platforms. There were 142 patients paired who had both platform reports. The three patients with Caris reports indicating "tissue with insufficient quantity" were excluded from comparative analysis. Data from platform reports were maintained in a secure network and in secure files. Data from Caris were collected into columns that corresponded to gene alterations of all frequencies, genes with unclassified mutations, specific TP53 alterations, and PD-L1 status. PD-L1 positivity was defined as intensity $\geq 2+$ and $\geq 5 \%$ of immunohistochemically stained cells. Similarly, detected alterations from Guardant 360 
were collected excluding alterations that were no longer detectable (compared to prior patient plasma samples). A representative sample of patients was highlighted, including all cancer types, proportions, and mutated genes (Table 3).

Table 3. Representative data sample of 43 (of 145) patients with accompanying patient numbers and ages. This table displays patients proportional to cancers of both common and rare subtypes. Genetic mutations detected via plasma cfDNA and tissue-based DNA NGS are displayed. Dashes indicate an absence of mutations detected. Time difference indicates gap between sample collections of both platforms in months (DPT). See appendix for abbreviations.

\begin{tabular}{|c|c|c|c|c|c|}
\hline PT & Diagnosis & Age & GDM & CDM & DPT \\
\hline 1 & $\begin{array}{l}\text { Adenoid cystic } \\
\text { carcinoma }\end{array}$ & 87 & EGFR, PIK3CA & - & 3 \\
\hline 3 & Breast adenocarcinoma & 36 & EGFR, PTEN, TP53 & $\begin{array}{l}\text { EGFR, PTEN, } \\
\text { TP53 }\end{array}$ & 11 \\
\hline 4 & Breast adenocarcinoma & 51 & $\begin{array}{c}\text { PTEN, FGFR2, FGFR1, } \\
\text { KRAS, PIK3CA, TP53, } \\
\text { BRCA2 }\end{array}$ & $\begin{array}{l}\text { BRCA2, CDK8, } \\
\text { PTEN, TP53 }\end{array}$ & 1 \\
\hline 11 & Breast adenocarcinoma & 71 & ARID1A, GNAS, TP53 & $\begin{array}{c}\text { ATM, BAP1, } \\
\text { BRCA2, } \\
\text { NOTCH1, TP53 }\end{array}$ & 1 \\
\hline 12 & $\begin{array}{c}\text { Carcinoma of unknown } \\
\text { primary }\end{array}$ & 27 & IDH2, TP53 & IDH2 & 1 \\
\hline 15 & Cholangiocarcinoma & 83 & $\begin{array}{l}\text { ATM, BRAF, SMAD4, } \\
\text { TP53 }\end{array}$ & SMAD4, TP53 & 8 \\
\hline 17 & Colorectal carcinoma & 31 & APC (x2), TP53, ARID1A & APC (x2), TP53 & 3 \\
\hline 21 & Colorectal carcinoma & 76 & NF1, ROS1, STK11 & $\begin{array}{c}\text { APC, KIT, } \\
\text { KRAS, TP53 }\end{array}$ & 1 \\
\hline 22 & Colorectal carcinoma & 58 & APC, KRAS, TP53 & - & 0 \\
\hline 35 & Colorectal carcinoma & 63 & $\begin{array}{l}\text { APC (x2), AR, EGFR, } \\
\text { FGFR1, KRAS, PIK3CA }\end{array}$ & $\begin{array}{c}\text { APC, ATM, } \\
\text { KRAS, PIK3CA }\end{array}$ & 13 \\
\hline 42 & Colorectal carcinoma & 56 & $\begin{array}{l}\text { APC, KRAS, MET, MYC, } \\
\text { RAF1, TP53 }\end{array}$ & APC, TP53 & 0 \\
\hline 46 & $\begin{array}{l}\text { Cutaneous squamous } \\
\text { cell carcinoma }\end{array}$ & 72 & $\begin{array}{l}\text { CCND1, EGFR, FGFR2, } \\
\text { KRAS, PIK3CA }\end{array}$ & $\begin{array}{c}\text { BRIP1, KRAS, } \\
\text { NOTCH1, } \\
\text { PIK3CA; FGF3, } \\
\text { FGF4, FGFR2, } \\
\text { NOTCH1 }\end{array}$ & 2 \\
\hline 48 & Endometrial carcinoma & 71 & PIK3CA & - & 57 \\
\hline 54 & $\begin{array}{c}\text { Esophageal } \\
\text { adenocarcinoma }\end{array}$ & 66 & KIT, TP53 & $\begin{array}{l}\text { AKT2, KIT, } \\
\text { CDK6, TP53 }\end{array}$ & 38 \\
\hline 57 & Gastric Adenocarcinoma & 52 & CCNE1 (x2), RAF1 & $\begin{array}{l}\text { ATM, BRCA2, } \\
\text { Her2/Neu } \\
\text { (ERBB2), TP53 }\end{array}$ & 5 \\
\hline 60 & $\begin{array}{l}\text { Gastrointestinal stromal } \\
\text { tumor }\end{array}$ & 70 & KIT & KIT & 0 \\
\hline 61 & Glioblastoma & 63 & CDKN2B, NOTCH1 & EGFR & 9 \\
\hline 63 & $\begin{array}{c}\text { Head and neck } \\
\text { squamous cell carcinoma }\end{array}$ & 63 & TP53 & KMT2D & 25 \\
\hline 69 & $\begin{array}{c}\text { Head and neck } \\
\text { squamous cell carcinoma }\end{array}$ & 63 & $\begin{array}{l}\text { CCND1, CDH1, MET, } \\
\text { PDGFRA, PIK3CA, TP53 }\end{array}$ & $\begin{array}{l}\text { CCND1, FGF3, } \\
\text { FGF4, KMT2C } \\
\text { (x2), TP53 }\end{array}$ & 5 \\
\hline 71 & $\begin{array}{l}\text { Hepatocellular } \\
\text { carcinoma }\end{array}$ & 63 & $\begin{array}{c}\text { ALK, AR, BRCA1, } \\
\text { GATA3, KIT, PIK3CA, } \\
\text { PTEN, TERT (x2), TP53 }\end{array}$ & $\begin{array}{l}\text { ARID2, FGF10, } \\
\text { TP53, BRCA2, } \\
\text { MCL1, RICTOR }\end{array}$ & 3 \\
\hline
\end{tabular}


Table 3. Cont.

\begin{tabular}{|c|c|c|c|c|c|}
\hline PT & Diagnosis & Age & GDM & CDM & DPT \\
\hline 72 & Melanoma & 36 & $\begin{array}{c}\text { BRAF (x2), EGFR, MET } \\
(\mathrm{x} 2), \text { NF1, NRAS, PTEN, } \\
\text { TERT }(\mathrm{x} 2)\end{array}$ & $\begin{array}{l}\text { BRAF, MET, } \\
\text { NF1, PTEN }\end{array}$ & 2 \\
\hline 78 & Melanoma & 68 & GNA11, MYC, NOTCH1 & BAP1, GNA11 & 6 \\
\hline 80 & Melanoma & 70 & ARID1A, NRAS & NRAS, SF3B1 & 4 \\
\hline 81 & Merkel cell carcinoma & 80 & PTEN, TP53 (x2) & - & 0 \\
\hline 82 & Neuroendocrine tumor & 68 & MET, PTPN11 & BRCA2 & 50 \\
\hline 84 & $\begin{array}{l}\text { Non-small cell lung } \\
\text { carcinoma }\end{array}$ & 71 & $\begin{array}{l}\text { CCNE1, CDKN2A, } \\
\text { EGFR, FGFR1, NF1, } \\
\text { PIK3CA, RB1, TP53 }\end{array}$ & $\begin{array}{l}\text { EGFR, PIK3R1, } \\
\text { TP53 }\end{array}$ & 1 \\
\hline 88 & Ovarian carcinoma & 57 & BRCA1, TP53 & TP53 & 0 \\
\hline 90 & Ovarian carcinoma & 77 & $\begin{array}{c}\text { CCNE1, EGFR, } \\
\text { NOTCH1, PIK3CA, } \\
\text { PTEN }\end{array}$ & PTEN, TP53 & 1 \\
\hline 93 & $\begin{array}{l}\text { Pancreatic ductal } \\
\text { adenocarcinoma }\end{array}$ & 53 & KRAS, NF1, TP53 & $\begin{array}{l}\text { CDKN2A, } \\
\text { KRAS }\end{array}$ & 8 \\
\hline 94 & $\begin{array}{l}\text { Pancreatic ductal } \\
\text { adenocarcinoma }\end{array}$ & 72 & CTNNB1, KRAS, TP53 & KRAS, TP53 & 11 \\
\hline 95 & $\begin{array}{l}\text { Pancreatic ductal } \\
\text { adenocarcinoma }\end{array}$ & 61 & $\begin{array}{l}\text { ARID1A, CDKN2A, } \\
\text { KRAS, TP53 }\end{array}$ & $\begin{array}{l}\text { KRAS, RNF43, } \\
\text { TP53 }\end{array}$ & 9 \\
\hline 110 & $\begin{array}{l}\text { Pancreatic ductal } \\
\text { adenocarcinoma }\end{array}$ & 67 & CDK6, FBXW7, KRAS & $\begin{array}{l}\text { AMER1, KRAS, } \\
\text { PALB2, SMAD4 }\end{array}$ & 1 \\
\hline 116 & $\begin{array}{l}\text { Pancreatic ductal } \\
\text { adenocarcinoma }\end{array}$ & 55 & CDKN2A, KRAS, TP53 & $\begin{array}{c}\text { CDKN1B, } \\
\text { CDKN2A, } \\
\text { KRAS, TP53 } \\
\end{array}$ & 4 \\
\hline 122 & Prostate adenocarcinoma & 51 & $\begin{array}{l}\text { AR, BRAF, CDK6, } \\
\text { FGFR1, MET, RAF1, } \\
\text { TP53 }\end{array}$ & TP53 & 17 \\
\hline 126 & Prostate adenocarcinoma & 56 & TP53 & - & 1 \\
\hline 129 & Prostate adenocarcinoma & 67 & $\begin{array}{c}\text { AR, BRAF, BRCA2, } \\
\text { CDK6, MET, MYC, } \\
\text { PDGFRA, ROS1, TP53 }\end{array}$ & TP53 & 0 \\
\hline 131 & Renal cell carcinoma & 52 & $\begin{array}{c}\text { BRCA2 (x2), CCND2, } \\
\text { TERT, VHL }\end{array}$ & BRCA2, VHL & 0 \\
\hline 133 & Sarcoma & 38 & - & MET & 7 \\
\hline 137 & Sarcoma & 20 & MTOR, TP53 & TP53 & 6 \\
\hline 139 & Sarcoma & 41 & TP53 & WRN & 0 \\
\hline 141 & $\begin{array}{c}\text { Small cell lung } \\
\text { carcinoma (SCLC) }\end{array}$ & 60 & $\begin{array}{c}\text { BRCA1, HRAS, RB1, } \\
\text { TP53 (x2) }\end{array}$ & $\begin{array}{l}\text { BRCA1, RB1, } \\
\text { TP53 }\end{array}$ & 2 \\
\hline 143 & $\begin{array}{l}\text { Transitional cell } \\
\text { carcinoma }\end{array}$ & 63 & PIK3CA, TP53 & MITF, PIK3CA & 20 \\
\hline 144 & $\begin{array}{l}\text { Transitional cell } \\
\text { carcinoma }\end{array}$ & 83 & FGFR1, TERT, TP53 & TP53 & 2 \\
\hline
\end{tabular}

\subsection{Cell Fate, Cell Survival, and Genome Maintenance Category Determination}

A recent comprehensive review provided categorization of 125 driver genes affected by subtle mutations (Table S2, Cancer Genome Landscapes) [13]. We integrated this data to define which genes stratify into CF, CS, and GM. Approximately 50 genes detected by Caris and Guardant360, which were not included in this review, were additionally stratified based on descriptions by the National Institute of Health (NIH) Genetics Home Reference database (https://ghr.nlm.nih.gov/). We formulated a guide to designate genes to the appropriate category (bottom of Table 1). Of special note, we classified TP53 as encompassing CS and GM; EP300 and GNAS were each classified in both CS and CF. We also compared 
the gene category scheme (Table S2 of Cancer Genome Landscapes) to our predictions based on the $\mathrm{NIH}$ database. Key attributes of CF included cellular determination; that of CS included promotion of angiogenesis, glucose uptake, and cellular proliferation; and that of GM included DNA repair and stability. Patients' genes were stratified into these three categories where the value represents the attributable quantity of alterations.

\subsection{Statistical Analysis}

Fisher's exact test was used for comparison of covariate cohorts to analyze associations and independence. All statistical analyses were done in R. The Fisher.test function in the R stats package was used to assess significance ( $p$ values). Correction for multiple testing ( $Q$ value) was performed using the Benjamini-Hochberg method for the results that had a significant $p$-value.

\subsection{Mutation Maps Generation}

Mutations in de-identified patients across different cancer subtypes and TP53 alterations detected by both platforms were plotted using Oncoprint.

\subsection{Concordance-Discordance Analysis}

Only the genes that were shared by both platforms $(n=66)$ were included in the concordance-discordance analysis. Concordance was defined as number of genes that were found to be altered in both platforms. Genes that were found mutated exclusively in Caris or Guardant360 determined discordance. We performed this analysis within each subject and across platforms from the pooled genes of 142 patients.

\section{Conclusions}

Our comparative analyses of tissue and ctDNA by NGS demonstrated trends in driver and passenger mutations, concordant and discordant genes, and GaDCUS. CS dominated in tumor pathobiology. The utility of treating patients based on the three core cellular processes (CS, GM, and CF) is imperative and requires further evaluation prospectively in clinical trials. In the future, genetic aberration-based cancer genome annotations must extend beyond NGS to proteomic networks [40-42]. A comprehensive molecular profile can serve as a guide for the optimal use of off-label drugs, design of relevant clinical trials, and can further the understanding of tumor heterogeneity and evolution to collectively improve patient survival [43]. Preempting tumor evolution via drug-resistance is a major challenge that needs further investigation. Planned serial biopsies of tissue and ctDNA at progression are mandatory in choosing the next best therapy.

Supplementary Materials: The following are available online at http://www.mdpi.com/2072-6694/12/3/701/s1, Table S1A: Two-way association analysis of each pair of cellular processes in individual platforms and combined platform results, Table S1B: The three cellular processes and TP53 mutation status for patient groups $>60-y r$ and $<60-y r$ in individual platforms and combined platform results, Table S1C: The three core cellular processes and their association with TP53 mutational status in all the patients, Table S2: Driver genes affected by subtle mutations (Cancer Genome Landscapes).

Author Contributions: K.L. contributed to the methods, software utilization, data curation, writing of the original manuscript draft, visualization, reviewing and editing, and project administration. R.K. contributed to data collection, visualization, formal analysis, reviewing and editing of manuscript, and validation of data. R.P. contributed to visualization, statistical analysis, formal analysis, reviewing and editing of manuscript, and validation of data. Y.C. contributed to visualization, statistical analysis, formal analysis, reviewing and editing of manuscript. H.M.B. contributed to the formal analysis, reviewing and editing of manuscript, and validation of the data. D.M. contributed to conceptualization, supervision, resources, formal analysis, reviewing and editing of manuscript, validation of data, project administration, and funding acquisition. All authors have read and agreed to the published version of the manuscript.

Funding: We wish to acknowledge the University of Arizona Cancer Center Support Grant (P30 CA023074) by the NCI.

Acknowledgments: We thank Larry Cooke for providing guidance in data input and processing of the data. 
Conflicts of Interest: Our study has no disclaimers regarding views held by our institution or prior works. The data analysis we provide is exclusive to this journal submission. Daruka Mahadevan is in the Speakers bureau-Caris Life Sciences and GuardantHealth. Moreover, the authors listed have no conflicts of interest or financial disclosures. The funders had no role in the design of the study; in the collection, analyses, or interpretation of data; in the writing of the manuscript, or in the decision to publish the results.

\section{Abbreviations for Tables and Figures}

\begin{tabular}{|c|c|}
\hline $\mathrm{ACC}$ & adenoid cystic carcinoma \\
\hline BAC & Breast adenocarcinoma \\
\hline $\mathrm{C}-\mathrm{CF}$ & Caris-cell fate \\
\hline C-CS & Caris-cell survival \\
\hline C-GM & Caris-genome maintenance \\
\hline CAC & cholangiocarcinoma \\
\hline CDM & Caris detected mutations \\
\hline CF & cell fate \\
\hline CRC & colorectal carcinoma \\
\hline CS & cell survival \\
\hline CSCC & cutaneous squamous cell carcinoma \\
\hline CUP & carcinoma of unknown primary \\
\hline $\mathrm{DPT}$ & difference between platform sample collection times (in months) \\
\hline EA & esophageal adenocarcinoma \\
\hline EC & endometrial carcinoma \\
\hline ES & esophageal squamous cell carcinoma \\
\hline $\mathrm{G}-\mathrm{CF}$ & Guardant360-cell fate \\
\hline G-CS & Guardant360-cell survival \\
\hline G-GM & Guardant360-genome maintenance \\
\hline GaDCUS & Guardant360 alterations detected in Caris unclassified section \\
\hline GBM & glioblastoma multiforme \\
\hline GDM & Guardant 360 detected mutations \\
\hline GIST & gastrointestinal stromal tumor \\
\hline GM & genome maintenance \\
\hline $\mathrm{HCC}$ & hepatocellular carcinoma \\
\hline HNSCC & head and neck squamous cell carcinoma \\
\hline MCC & merkel cell carcinoma \\
\hline NET & neuroendocrine tumor \\
\hline NGS & next generation sequencing \\
\hline NSCLC & non-small cell lung cancer \\
\hline PA & pancreatic adenocarcinoma \\
\hline PT & patient study number \\
\hline RCC & renal cell carcinoma \\
\hline SCLC & small cell lung cancer \\
\hline TCC & transitional cell carcinoma \\
\hline Q & quantity of patients per cancer subtype \\
\hline
\end{tabular}

\section{References}

1. Schmidt, K.T.; Chau, C.H.; Price, U.K.; Figg, W.D. Precision oncology medicine: The clinical relevance of patient-specific biomarkers used to optimize cancer treatment. J. Clin. Pharmacol. 2016, 56, 1484-1499. [CrossRef] [PubMed]

2. Tsimberidou, A.M.; Hong, D.S.; Ye, Y.; Cartwright, C.; Wheler, J.J.; Falchook, G.S.; Naing, A.; Fu, S.; Piha-Paul, S.; Janku, F.; et al. Initiative for Molecular Profiling and Advanced Cancer Therapy (IMPACT): An MD Anderson Precision Medicine Study. JCO Precis. Oncol. 2017. [CrossRef] [PubMed]

3. Rodon, J.; Soria, J.-C.; Berger, R.; Miller, W.H.; Rubin, E.; Kugel, A.; Tsimberidou, A.; Saintigny, P.; Ackerstein, A.; Braña, I.; et al. Genomic and transcriptomic profiling expands precision cancer medicine: The WINTHER trial. Nat. Med. 2019, 25, 751-758. [CrossRef] [PubMed] 
4. Chapman, P.B.; Hauschild, A.; Robert, C.; Haanen, J.B.; Ascierto, P.; Larkin, J.; Dummer, R.; Garbe, C.; Testori, A.; Maio, M.; et al. Improved survival with vemurafenib in melanoma with BRAF V600E mutation. N. Engl. J. Med. 2011, 364, 2507-2516. [CrossRef] [PubMed]

5. Kwak, E.L.; Bang, Y.-J.; Camidge, D.R.; Shaw, A.T.; Solomon, B.; Maki, R.G.; Ou, S.-H.I.; Dezube, B.J.; Janne, P.A.; Costa, D.; et al. Anaplastic lymphoma kinase inhibition in non-small-cell lung cancer. N. Engl. J. Med. 2010, 363, 1693-1703. [CrossRef] [PubMed]

6. Deben, C.; Van Der Steen, N.; Lardon, F.; De Beeck, K.O.; Hermans, C.; Deschoolmeester, V.; Pauwels, P.; Wouters, A.; Peeters, M.; Rolfo, C.C.; et al. Deep sequencing of the TP53 gene reveals a potential risk allele for non-small cell lung cancer and supports the negative prognostic value of TP53 variants. Tumor Boil. 2017, 39. [CrossRef]

7. Wheler, J.J.; Janku, F.; Naing, A.; Li, Y.; Stephen, B.; Zinner, R.; Subbiah, V.; Fu, S.; Karp, D.; Falchook, G.S.; et al. TP53 Alterations Correlate with Response to VEGF/VEGFR Inhibitors: Implications for Targeted Therapeutics. Mol. Cancer Ther. 2016, 15, 2475-2485. [CrossRef]

8. Oltmann, J.; Heselmeyer-Haddad, K.; Hernandez, L.S.; Meyer, R.; Torres, I.; Hu, Y.; Doberstein, N.; Killian, J.K.; Petersen, D.; Zhu, Y.J.; et al. Aneuploidy, TP53 mutation, and amplification of MYC correlate with increased intratumor heterogeneity and poor prognosis of breast cancer patients. Genes Chromosom. Cancer 2018, 57, 165-175. [CrossRef]

9. Melaiu, O.; Mina, M.; Chierici, M.; Boldrini, R.; Jurman, G.; Romania, P.; D'Alicandro, V.; Benedetti, M.C.; Castellano, A.; Liu, T.; et al. PD-L1 Is a Therapeutic Target of the Bromodomain Inhibitor JQ1 and, Combined with HLA Class I, a Promising Prognostic Biomarker in Neuroblastoma. Clin. Cancer Res. 2017, 23, 4462-4472. [CrossRef]

10. Li, J.; Chen, L.; Xiong, Y.; Zheng, X.; Xie, Q.; Zhou, Q.; Shi, L.; Wu, C.; Jiang, J.; Wang, H. Knockdown of PD-L1 in Human Gastric Cancer Cells Inhibits Tumor Progression and Improves the Cytotoxic Sensitivity to CIK Therapy. Cell. Physiol. Biochem. 2017, 41, 907-920. [CrossRef]

11. Jiao, S.; Xia, W.; Yamaguchi, H.; Wei, Y.; Chen, M.-K.; Hsu, J.-M.; Hsu, J.L.; Yu, W.-H.; Du, Y.; Lee, H.-H.; et al. PARP Inhibitor Upregulates PD-L1 Expression and Enhances Cancer-Associated Immunosuppression. Clin. Cancer Res. 2017, 23, 3711-3720. [CrossRef] [PubMed]

12. De Bono, J.S.; Ashworth, A. Translating cancer research into targeted therapeutics. Nature 2010, 467, 543-549. [CrossRef] [PubMed]

13. Vogelstein, B.; Papadopoulos, N.; Velculescu, V.E.; Zhou, S.; Diaz, L.A.; Kinzler, K.W. Cancer Genome Landscapes. Science 2013, 339, 1546-1558. [CrossRef] [PubMed]

14. Lanman, R.B.; Mortimer, S.A.; Zill, O.A.; Sebisanovic, D.; Lopez, R.; Blau, S.; Collisson, E.A.; Divers, S.G.; Hoon, D.S.; Kopetz, S.; et al. Analytical and Clinical Validation of a Digital Sequencing Panel for Quantitative, Highly Accurate Evaluation of Cell-Free Circulating Tumor DNA. PLoS ONE 2015, 10, e0140712. [CrossRef]

15. Carr, T.; McEwen, R.; Dougherty, B.; Johnson, J.H.; Dry, J.R.; Lai, Z.; Ghazoui, Z.; Laing, N.M.; Hodgson, D.R.; Cruzalegui, F.; et al. Defining actionable mutations for oncology therapeutic development. Nat. Rev. Cancer 2016, 16, 319-329. [CrossRef]

16. Yun, J.; Rago, C.; Cheong, I.; Pagliarini, R.; Angenendt, P.; Rajagopalan, H.; Schmidt, K.; Willson, J.K.V.; Markowitz, S.; Zhou, S.; et al. Glucose Deprivation Contributes to the Development of KRAS Pathway Mutations in Tumor Cells. Science 2009, 325, 1555-1559. [CrossRef]

17. Kawauchi, K.; Araki, K.; Tobiume, K.; Tanaka, N. p53 regulates glucose metabolism through an IKK-NF-kB pathway and inhibits cell transformation. Nature 2008, 10, 611-618. [CrossRef]

18. Gao, Y.; Chen, Z.-L.; Li, J.-G.; Hu, X.-D.; Shi, X.-J.; Sun, Z.-M.; Zhang, F.; Zhao, Z.-R.; Li, Z.-T.; Liu, Z.-Y.; et al. Genetic landscape of esophageal squamous cell carcinoma. Nat. Genet. 2014, 46, 1097-1102. [CrossRef]

19. Hagemann, I.; Devarakonda, S.; Lockwood, C.; Spencer, D.H.; Guebert, K.; Bredemeyer, A.J.; Al-Kateb, H.; Nguyen, T.T.; Duncavage, E.J.; Cottrell, C.E.; et al. Clinical next-generation sequencing in patients with non-small cell lung cancer. Cancer 2014, 121, 631-639. [CrossRef]

20. Olivier, M.; Petitjean, A.; De Fromentel, C.C.; Hainaut, P.; Ayed, A.; Hupp, T. TP53 Mutations in Human Cancers: Selection versus Mutagenesis. Sphingolipid-Mediat. Signal Transduct. 2010, 1, 1-18.

21. Tsoulos, N.; Papadopoulou, E.; Metaxa-Mariatou, V.; Tsaousis, G.N.; Efstathiadou, C.; Tounta, G.; Scapeti, A.; Bourkoula, E.; Zarogoulidis, P.; Pentheroudakis, G.; et al. Tumor molecular profiling of NSCLC patients using next generation sequencing. Oncol. Rep. 2017, 38, 3419-3429. [CrossRef] [PubMed] 
22. Kikuchi-Yanoshita, R.; Konishi, M.; Ito, S.; Seki, M.; Tanaka, K.; Maeda, Y.; Iino, H.; Fukayama, M.; Koike, M.; Mori, T. Genetic changes of both p53 alleles associated with the conversion from colorectal adenoma to early carcinoma in familial adenomatous polyposis and non-familial adenomatous polyposis patients. Cancer Res. 1992, 52, 3965-3971. [PubMed]

23. Schwaederle, M.; Lazar, V.; Validire, P.; Hansson, J.; Lacroix, L.; Soria, J.-C.; Pawitan, Y.; Kurzrock, R.; Vladimir, L. VEGF-A Expression Correlates with TP53 Mutations in Non-Small Cell Lung Cancer: Implications for Antiangiogenesis Therapy. Cancer Res. 2015, 75, 1187-1190. [CrossRef] [PubMed]

24. Ojesina, A.; Lichtenstein, L.; Freeman, S.; Pedamallu, C.S.; Rosshandler, I.I.; Pugh, T.J.; Cherniack, A.D.; Ambrogio, L.; Cibulskis, K.; Bertelsen, B.; et al. Landscape of genomic alterations in cervical carcinomas. Nature 2013, 506, 371-375. [CrossRef] [PubMed]

25. Feng, M.; Xiong, G.; Cao, Z.; Yang, G.; Zheng, S.; Song, X.; You, L.; Zheng, L.; Zhang, T.; Zhao, Y. PD-1/PD-L1 and immunotherapy for pancreatic cancer. Cancer Lett. 2017, 407, 57-65. [CrossRef] [PubMed]

26. Kuderer, N.M.; Burton, K.A.; Blau, S.; Rose, A.L.; Parker, S.; Lyman, G.H.; Blau, C.A. Comparison of 2 Commercially Available Next-Generation Sequencing Platforms in Oncology. JAMA Oncol. 2017, 3, 996-998. [CrossRef]

27. Taavitsainen, S.; Annala, M.; Ledet, E.; Beja, K.; Miller, P.J.; Moses, M.; Nykter, M.; Chi, K.N.; Sartor, O.; Wyatt, A.W. Evaluation of Commercial Circulating Tumor DNA Test in Metastatic Prostate Cancer. JCO Precis. Oncol. 2019, 3, 1-9. [CrossRef]

28. Lawrence, M.S.; Stojanov, P.; Mermel, C.H.; Robinson, J.T.; Garraway, L.A.; Golub, T.R.; Meyerson, M.; Gabriel, S.B.; Lander, E.S.; Getz, G. Discovery and saturation analysis of cancer genes across 21 tumor types. Nature 2014, 505, 495-501. [CrossRef]

29. Zill, O.A.; Banks, K.C.; Fairclough, S.R.; Mortimer, S.A.; Vowles, J.V.; Mokhtari, R.; Gandara, D.R.; Mack, P.C.; Odegaard, J.I.; Nagy, R.J.; et al. The Landscape of Actionable Genomic Alterations in Cell-Free Circulating Tumor DNA from 21,807 Advanced Cancer Patients. Clin. Cancer Res. 2018, 24, 3528-3538. [CrossRef]

30. Page, K.; Guttery, D.; Garcia, D.F.; Hills, A.; Hastings, R.; Luo, J.; Goddard, K.; Shahin, V.; Woodley-Barker, L.; Rosales, B.M.; et al. Next Generation Sequencing of Circulating Cell-Free DNA for Evaluating Mutations and Gene Amplification in Metastatic Breast Cancer. Clin. Chem. 2017, 63, 532-541. [CrossRef]

31. Merker, J.D.; Oxnard, G.R.; Compton, C.; Diehn, M.; Hurley, P.; Lazar, A.; Lindeman, N.; Lockwood, C.; Rai, A.J.; Schilsky, R.L.; et al. Circulating Tumor DNA Analysis in Patients With Cancer: American Society of Clinical Oncology and College of American Pathologists Joint Review. J. Clin. Oncol. 2018, 36, 1631-1641. [CrossRef] [PubMed]

32. Strickler, J.H.; Loree, J.; Ahronian, L.G.; Parikh, A.R.; Niedzwiecki, N.; Pereira, A.; McKinney, M.; Korn, W.M.; Atreya, C.E.; Banks, K.C.; et al. Genomic Landscape of Cell-Free DNA in Patients with Colorectal Cancer. Cancer Discov. 2017, 8, 164-173. [CrossRef] [PubMed]

33. Tokheim, C.J.; Papadopoulos, N.; Kinzler, K.W.; Vogelstein, B.; Karchin, R. Evaluating the evaluation of cancer driver genes. Proc. Natl. Acad. Sci. USA 2016, 113, 14330-14335. [CrossRef] [PubMed]

34. Carter, P.; Alifrangis, C.; Cereser, B.; Chandrasinghe, P.; Belluz, L.D.B.; Herzog, T.; Levitan, J.; Moderau, N.; Schwartzberg, L.; Tabassum, N.; et al. Does molecular profiling of tumors using the Caris molecular intelligence platform improve outcomes for cancer patients? Oncotarget 2018, 9, 9456-9467.

35. Rothwell, D.G.; Ayub, M.; Cook, N.; Thistlethwaite, F.; Carter, L.; Dean, E.; Smith, N.; Villa, S.; Dransfield, J.; Clipson, A.; et al. Utility of ctDNA to support patient selection for early phase clinical trials: The TARGET study. Nat. Med. 2019, 25, 738-743. [CrossRef]

36. Slavin, T.P.; Banks, K.C.; Chudova, D.; Oxnard, G.R.; Odegaard, J.I.; Nagy, R.J.; Tsang, K.W.K.; Neuhausen, S.L.; Gray, S.W.; Cristofanilli, M.; et al. Identification of Incidental Germline Mutations in Patients With Advanced Solid Tumors Who Underwent Cell-Free Circulating Tumor DNA Sequencing. J. Clin. Oncol. 2018, 36, 3459-3465. [CrossRef]

37. Zhang, X.; Mar, V.; Zhou, W.; Harrington, L.; Robinson, M. Telomere shortening and apoptosis in telomerase-inhibited human tumor cells. Genome Res. 1999, 13, 2388-2399. [CrossRef]

38. Tamborero, D.; Gonzalez-Perez, A.; Perez-Llamas, C.; Deu-Pons, J.; Kandoth, C.; Reimand, J.; Lawrence, M.S.; Getz, G.; Bader, G.D.; Ding, L.; et al. Comprehensive identification of mutational cancer driver genes across 12 tumor types. Sci. Rep. 2013, 3, 2650. [CrossRef] 
39. Dees, N.D.; Zhang, Q.; Kandoth, C.; Wendl, M.C.; Schierding, W.; Koboldt, D.C.; Mooney, T.B.; Callaway, M.B.; Dooling, D.; Mardis, E.R.; et al. MuSiC: Identifying mutational significance in cancer genomes. Genome Res. 2012, 22, 1589-1598. [CrossRef]

40. Shannon, P.; Markiel, A.; Ozier, O.; Baliga, N.S.; Wang, J.T.; Ramage, D.; Amin, N.; Schwikowski, B.; Ideker, T. Cytoscape: A Software Environment for Integrated Models of Biomolecular Interaction Networks. Genome Res. 2003, 13, 2498-2504. [CrossRef]

41. Pan, S.; Brentnall, T.A.; Kelly, K.; Chen, R. Tissue proteomics in pancreatic cancer study: Discovery, emerging technologies, and challenges. Proteomics 2013, 13, 710-721. [CrossRef] [PubMed]

42. Doll, S.; Gnad, F.; Mann, M. The Case for Proteomics and Phospho-Proteomics in Personalized Cancer Medicine. Proteom. Clin. Appl. 2019, 13. [CrossRef] [PubMed]

43. Lee, S.; Lee, S.; Ouellette, S.; Park, W.-Y.; Lee, E.A.; Park, P.J. NGSCheckMate: Software for validating sample identity in next-generation sequencing studies within and across data types. Nucleic Acids Res. 2017, 45. [CrossRef] [PubMed]

(C) 2020 by the authors. Licensee MDPI, Basel, Switzerland. This article is an open access article distributed under the terms and conditions of the Creative Commons Attribution (CC BY) license (http://creativecommons.org/licenses/by/4.0/). 